\title{
PENGARUH MEDIA FLIPCHART TERHADAP PEMAHAMAN KONSEP IPA KELAS IV SDN KALIDERES 09 PAGI JAKARTA BARAT
}

\author{
Lailatul Barkah \\ Universitas Muhammadiyah Tangerang \\ lailbarkah@gmail.com
}

\begin{abstract}
ABSTRAK
Penelitian ini bertujuan untuk mengetahui pengaruh media flipchart terhadap pemahaman konsep siswa kelas IV SDN Kalideres 09 Pagi Jakarta Barat. Penelitian ini menggunakan metode penelitian quasi eksperimental. Subjek populasi dalam penelitian ini adalah seluruh siswa kelas IV SDN Kalideres 09 Pagi yang berjumlah 59 siswa yaitu kelas IV A yang berjumlah 29 siswa sebagai kelas kontrol dan kelas IV B yang berjumlah 30 siswa sebagai kelas eksperimen. Teknik pengumpulan data dengan menggunakan instrument soal tes yang terdiri dari 8 soal valid dan reliabel. Berdasarkan analisis statistik postest kelas eksperimen dan kelas kontrol dengan menggunakan uji-t dengan taraf 5\% didapatkan hasil thitung $=3,988$ $>$ tabel $(0,05 ; \mathrm{N}-2)=2,024$. Dari hasil penelitian tersebut dapat disimpulkan bahwa terdapat perbedaan pemahaman konsep IPA kelas IV SDN Kalideres 09 Pagi Jakarta Barat pada siswa yang diberikan media Flipchart dengan siswa yang diberikan pembelajaran secara konvensional. Dengan kata lain pembelajaran dengan media Flipchart memberikan pengaruh positif terhadap pemahaman konsep IPA kelas IV SDN Kalideres 09 Pagi Jakarta Barat.
\end{abstract}

Kata kunci: Pemahaman Konsep, media flipchart, IPA

\begin{abstract}
This study aims to determine the effect of flipchart media on the understanding of the fourth grade students of SDN Kalideres 09 Pagi West Jakarta. This study uses a quasi-experimental research method. The population subjects in this study were all fourth grade students at SDN Kalideres 09 Pagi, totaling 59 students, namely class IV A, which consisted of 29 students as the control class and class IV B, which consisted of 30 students as the experimental class. The data collection technique used a test question instrument consisting of 8 valid and reliable questions. Based on the posttest statistical analysis of the experimental class and the control class using a t-test with a level of 5\%, the results obtained were tcount $=3.988>{ }^{t}$ table $(0.05 ; \mathrm{N}-2)=2.024$. From the results of this study, it can be concluded that there are differences in understanding the concept of science for class IV SDN Kalideres 09 Pagi West Jakarta on students who are given Flipchart media with students who are given conventional learning. In other words, learning with Flipchart media has a positive influence on understanding the fourth grade science concept at SDN Kalideres 09 Pagi, West Jakarta.
\end{abstract}

Keywords: Concept Understanding, flipchart media, IPA

\section{PENDAHULUAN}

Pendidikan adalah pondasi dalam kehidupan yang harus dibangun dengan sebaik mungkin. Dalam pendidikan terdapat kegiatan atau suatu proses yang mencakup segala aktivitas yang akan memudahkan dalam kehidupan masyarakat. Pendidikan bertujuan mengembangkan potensi dan mencerdaskan kehidupan individu dengan lebih baik. Berdasarkan tujuan tersebut diharapkan mereka yang mempunyai pendidikan dengan baik dapat memiliki pengetahuan, kreativitas, keterampilan, kemandirian, dan menjadi pribadi yang lebih bertanggung jawab yang akan bermanfaat untuk dirinya sendiri ataupun masyarakat. Pendidikan sebagai usaha sadar dan terencana membuktikan bahwa pendidikan merupakan suatu proses yang disengaja dan dipikirkan secara sungguh-sungguh, kegiatan pendidikan 


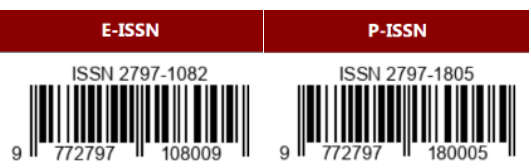

Volume 2 Nomor 1 (Desember 2021 - Februari 2022)

harus disadari dan direncanakan dengan baik agar mewujudkan suasana belajar dan proses pembelajaran agar siswa aktif mengembangkan potensi dirinya. Dalam pendidikan terdapat mata pelajaran yang wajib diajarkan mulai dari tingkat pendidikan Sekolah dasar hingga Perguruan Tinggi yakni salah satunya mata pelajaran Ilmu Pengetahuan Alam (IPA).

Ilmu Pengetahuan Alam (IPA) berhubungan dengan cara mencari tahu tentag alam secara sistematis, sehingga IPA bukan hanya penguasaan kumpulan pengetahuan yang berupa fakta-fakta, konsep-konsep, atau prinsip-prinsip saja tetapi juga merupakan suatu proses penemuan. Pendidikan IPA diharapkan dapat menjadi wahana bagi peserta didik untuk mempelajari diri sendiri dan alam sekitar, serta prospek pengembangan lebih lanjut dalam menerapkannya didalam kehidupan seharihari.

Berdasarkan hasil observasi dan wawancara dengan guru kelas IV SDN Kalideres 09 Pagi, diketahui bahwa dalam pembelajaran IPA di kelas IV masih ada permasalahan, yakni kurangnya pemahaman konsep IPA yang belum sesuai dengan KKM (Kriteria Ketuntasan Minimum) yaitu 70. Dalam hasil ulangan harian yang telah diperoleh dari kelas IV A 29 siswa dan kelas IV B sebanyak 30 siswa. Bahwa hanya 25 siswa atau 42,4\% yang mencapai KKM (Kriteria Ketuntasan Minimum), sedangkan 34 siswa atau 57,6\% siswa lainnya masih belum mencapai KKM (Kriteria Ketuntasan Minimum). Dengan melihat hasil nilai ulangan harian tersebut dapat dinilai bahwa pemahaman konsep IPA siswa kelas IV SDN Kalideres 09 Pagi masih rendah. Hal tersebut terlihat dari kurangnya keaktifan peserta didik di dalam proses pembelajaran IPA dan kurangnya keterampilan guru dalam memberikan materi dan menciptakan suasana belajar yang menyebabkan proses belajar mengajar hanya berpusat pada guru dan hanya didukung dengan media buku. Salah satu media pembelajaran yang dapat digunakan untuk membantu meningkatkan pemahaman konsep IPA dengan menggunakan media flipchart. Media flipchart merupakan media cetak yang sangat sederhana dan cukup efektif. Sederhana dilihat dari proses pembuatannya dan penggunaannya yang relatif mudah. Dengan memanfaatkan bahan kertas yang mudah dijumpai disekitar kita. Selain itu, media flipchart merupakan media visual yang menarik perhatian peserta didik, memperjelas sajian ide, menggambarrkan atau menghiasi fakta yang mungkin akan cepat dilupakan jika tidak divisualkan. Berdasarkan latar belakang masalah yang telah dipaparkan di atas, maka peneliti tertarik untuk melakukan penelitian yang berjudul "Pengaruh Media Flipchart Terhadap Pemahaman Konsep IPA Kelas IV SDN Kalideres 09 Pagi Jakarta Barat”.

Pemahaman konsep adalah kemampuan menangkap pengertian-pengertian seperti mampu mengungkapkan suatu materi yang disajikan kedalam bentuk yang lebih dipahami, mampu memberikan interprestasi, dan mengaplikasikannya (Hamdani, Kurniati, \& Sakti 2012).

Sedangkan Duffin dan Simpson (2000) menyatakan bahwa pemahaman konsep sebagai kemampuan siswa untuk: (1) menjelaskan konsep, dapat diartikan siswa mampu untuk mengungkapkan kembali apa yang dikomunikasikan kepadanya, (2) menggunakan konsep pada berbagai situai yang berbeda, dan (3) mengembangkan beberapa akibat dari adanya suatu konsep (Kesumawati, 2008). Hal tersebut diperkuat 


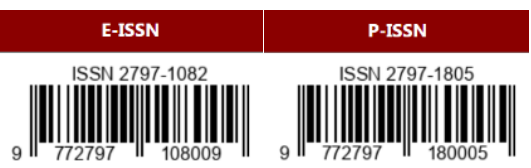

Volume 2 Nomor 1 (Desember 2021 - Februari 2022)

oleh pendapat Arsyad (2011) yang menyatakan jika media pembelajaran memberikan keesamaan pengalaman kepada setiap siswa terkait peristiwa di sekitarnya. Dengan demikian, siswa mampu mengungkapkan kembali materi yang dipelajari dengan pemahaman konsep yang dapat diaplikasikan untuk menyelesaikan masalah dalam pembelajaran.

Ilmu Pengetahuan Alam

merupakan ilmu yang berhubungan dengan cara mencari tahu tentang alam sekitar secara sistematis, sehingga IPA bukan hanya penguasaan kumpulan pengetahuan yang berupa fakta-fakta, konsep-konsep, atau prinsip-prinsip saja tetapi juga merupakan suatu proses penemuan (BSNP, 2006). Sedangkan menurut Yumarlin (2013) yang berpendapat bahwa mata pelajaran IPA diharapkan menjadi wahana bagi peserta didik untuk mempelajari diri sendiri dan alam sekitar, serta prospek pengembangan lebih lanjut dalam menerapkannya di dalam kehidupan sehari-hari.

"Rudi dan Cepi (2019) menambahkan, "flipchart adalah lembaran-lembaran kertas menyerupai album atau kalender berukuran $50 \times 75 \mathrm{~cm}$, atau ukuran yang lebih kecil $21 \times$ $28 \mathrm{~cm}$ " (h. 87). Menurut Mustaji (2006) media flipchart adalah salah satu jenis media yang penyajikannya sangat sederhana yaitu berukuran 50-75 berisi gambar, huruf, angka berkaitan dengan materi yang diajarkan. Untuk melihat flipchart direncanakan tempat yang sesuai dimana dan bagaimana flipchart ditempatkan misalnya: dipajang di papan tulis harus terbaca oleh semua siswa. Sedangkan menurut Suyatno media flipchart adalah kumpulan ringkasan, skema, gambar, tabel yang dibuka secara berurutan berdasarkan topik materi pembelajaran. Bahan flipchart biasanya kertas yang mudah dibuka-buka, mudah ditulisi, dan berwarna cerah. Untuk daya tarik, flipchart dapat dicetak dengan aneka warna dan variasi desain (Marhamah, 2016).

\section{METODE}

Tempat penelitian di lakukan di kelas IV SDN Kalideres 09 Pagi Jakarta Barat. Waktu penelitian ini dilakukan di bulan maret 2021 - Desember 2021. Pendekatan dalam penelitian ini adalah penelitian kuantitatif, sedangkan jenis metode penelitian yang digunakan adalah "Quasi Eksperimen Design”. Rancangan eksperimen yang dilakukan dalam penelitian ini adalah termasuk jenis "Nonequivalent Control Design”. Pengumpulan data yang digunakan berupa soal berbentuk essay. Populasi dalam penelitian ini adalah siswa kelas IV SDN Kalideres 09 Pagi Jakarta Barat. Adapun siswa kelas IV yang berjumlah 59 siswa yang terdiri dari kelas IV A 30 siswa dan kelas IV B 29 siswa. Sampel penelitian ini adalah siswa kelas IV A dan IV B SDN Kalideres 09 Pagi Jakarta Barat, adapun sampel dalam penelitian ini adalah 40 siswa yang terdiri dari kelas IV A 20 siswa dan kelas IV B 20 siswa. Teknik yang digunakan dalam pengambilan sampel adalah sampel jenuh. Teknik analisis data menggunakan metode statistik deskriptif dan statistik inferensial. Dalam statistik deskriptif terdapat tabel distribusi frekuensi, grafik/gambar, dan pemusatan data. Sedangkan statistik inferensial terdapat uji normalitas menggunakan Chi kuadrat, uji homogenitas dengan uji $\mathrm{F}$, Uji hipotesis dengan Uji T.

\section{HASIL PENELITIAN}

Soal essat yang telah dibuat oleh peneliti, sebelumnya dilakukan uji coba instrumen kepada siswa kelas V SDN 
Kalideres 09 Pagi Jakarta Barat yang berjumlah 30 siswa. Kemudian, soal tersebut terdistribusi berdasarkan indikator dari varabel pemahaman konsep. Setelah soal essay diuji cobakan, kemudian hasilnya di uji validitas dan reliabilitas, hasilnya dari 10 soal essay yang valid terdapat 8 soal essay, pertanyaan pada soal essay tersebut layak digunakan dan telah memenuhi syarat validitas dan reliabilitas. Dalam tahap pengumpulan data peneliti menggunakan uji validitas butir soal essay, reliabilitas soal essay sebelum instrumen soal esssay ini kemudian diujikan pada sampel penelitian. Pengujian statistik inferensial menggunakan uji normalitas dan uji homogenitas. Uji normalitas dapat di lihat pada tabel 1 sebagai berikut :

Tabel Hasil Uji Normalitas

\begin{tabular}{|l|l|l|l|}
\hline Kelompok & $\begin{array}{l}\boldsymbol{x}^{\mathbf{2}} \\
\text { hitung }\end{array}$ & $\begin{array}{l}\boldsymbol{x}^{\mathbf{2}} \text { tabel (5\%; } \\
\mathbf{K 1 )}=\mathbf{( 5 \% ; 5 )}\end{array}$ & Keterangan \\
\hline Eksperimen & 10,16 & 11,07 & $\begin{array}{l}\text { Berdistribusi } \\
\text { Normal }\end{array}$ \\
\hline Kontrol & 1,96 & 11,07 & $\begin{array}{l}\text { Berdistribusi } \\
\text { Normal }\end{array}$ \\
\hline
\end{tabular}

\begin{tabular}{|l|l|l|l|}
\hline Kelompok & $\begin{array}{l}\boldsymbol{x}^{\mathbf{2}} \\
\text { hitung }\end{array}$ & $\begin{array}{l}\boldsymbol{x}^{\mathbf{2}} \text { tabel (5\%; } \\
\mathbf{K 1})=(\mathbf{5 \%} ; \mathbf{5})\end{array}$ & Keterangan \\
\hline Eksperimen & 4,53 & 11,07 & $\begin{array}{l}\text { Berdistribusi } \\
\text { Normal }\end{array}$ \\
\hline Kontrol & 3,96 & 11,07 & $\begin{array}{l}\text { Berdistribusi } \\
\text { Normal }\end{array}$ \\
\hline
\end{tabular}

Berdasarkan tabel diatas terlihat uji normalitas data pretest pada kelas eksperimen dengan $x^{2}$ hitung $=10,16<11,07=x^{2}$ tabel, maka $\mathrm{H}_{0}$ diterima sehingga dapat diartikan data pretest kelas eksperimen berdistribusi normal. Begitu pula pada pretest kelas kontrol $x^{2}{ }_{\text {hitung }}$ $=1,96<11,07=x^{2}$ tabel, maka $\mathrm{H}_{0}$ diterima sehingga dapat diartikan data pretest kelas kontrol berdistribusi normal. Jadi dapat disimpulkan bahwa pada pretest kelas eksperimen dan kontrol berdistribusi normal.
Sedangkan berdasarkan tabel diatas terlihat hasil uji normalitas data postest pada kelas eksperimen dengan $x^{2}$ hitung $=4,53<$ $11,07=x^{2}$ tabel, maka $\mathrm{H}_{0}$ diterima sehingga dapat diartikan data postest kelas eksperimen berdistribusi normal. Begitu pula pada data postest kelas kontrol $x^{2}{ }_{\text {hitung }}=3,96<11,07=$ $x^{2}$ tabel, maka $\mathrm{H}_{0}$ diterima sehingga dapat diartikan data postest kelas kontrol berdistribusi normal. Jadi dapat disimpulkan bahwa pada data postest kelas eksperimen dan kelas kontrol berdistribusi normal.

Berdasarkan penelitian jumlah siswa kelas eksperimen yang mengikuti pretest berjumlah 20 siswa. Dari 20 siswa kelas eksperimen di peroleh hasil nilai maksimum (Dmax) 35 dan nilai minimum (Dmin) 23 sehingga dapat diperoleh rentang data $(r)=12$, banyak kelas $(\mathrm{k})=6$, interval $(\mathrm{i})=2$, rata-rata $($ mean $)=28,90$, modus $($ mo $)=30,50$, median $(\mathrm{me})=29,17$, varians $(\mathrm{s} 2)=15,30$ dan simpangan baku $(\mathrm{s})=3,91$.Sedangkan berdasarkan hasil observasi jumlah siswa kelas kontrol yang mengikuti pretest berjumlah 20 siswa. Dari 20 siswa kelas kontrol diperoleh hasil nilai maksimum (Dmax) 39 dan nilai minimum (Dmin) 17 sehingga diperoleh rentang data $(r)=22$, banyak kelas $(\mathrm{k})=6$, interval $(\mathrm{i})=4$, rata-rata $($ mean $)=29,90$, modus $(\mathrm{mo})=31,50$, median $(\mathrm{me})=31,07$, varians $(\mathrm{s} 2)=27,41 \mathrm{dan}$ simpangan baku $(\mathrm{s})=5,24$.Dapat dipeeroleh hasil perhitungan uji-t pretest menunjukkan bahwa kedua kelas eksperimen dan kelas kontrol yang diuji dengan taraf signifikansi a $=0,05$ dan diperoleh $t_{\text {hitung }}=-0,667$ sedangkan $\mathrm{t}_{\text {tabel }(0,05 ; \mathrm{N}-2)}=2,024$ karena $\mathrm{t}_{\text {hitung }}<\mathrm{t}_{\text {tabel }}$ maka $\mathrm{H}_{0}$ diterima artinya rata-rata pretest kelompok eksperimen sama dengan kelompok kontrol. Maka dapat disimpulkan bahwa pemberian pretest pada kelas eksperimen dan kelas 
kontrol tidak terdapat perbedaan yang signifikan.

Berdasarkan penelitian jumlah siswa kelas eksperimen yang mengikuti postest berjumlah 20 siswa. Dari 20 siswa di kelas eksperimen memperoleh nilai maksimum (Dmax) 95 dan nilai minimum (Dmin) 47 sehingga dapat diperoleh rentang data $(r)=48$, banyak kelas $(\mathrm{k})=6$, interval $(\mathrm{i})=8$, rata-rata $($ mean $)=75,00$, modus $($ mo $)=73,50$, median $(\mathrm{me})=73,07$, varians $(\mathrm{s} 2)=141,26$, simpangan baku $(\mathrm{s})=11,89$. Berdasarkan penelitian jumlah siswa kelas kontrol yang mengikuti postest berjumlah 20 siswa. Dari 20 siswa dikelas kontrol memperoleh nilai maksimum (Dmax) 83 dan nilai minimum (Dmin) 38 sehingga dapat diperoleh rentang data $(\mathrm{r})=45$, banyak kelas $(\mathrm{k})=6$, interval (i) $=8$, rata-rata $($ mean $)=59,50$, modus $($ mo $)=$ 55,50, median $(\mathrm{me})=56,07$, varians $(\mathrm{s} 2)=$ 160,84, simpngan baku (s) $=12,68$. Berdasarkan hasil perhitungan untuk siswa yang mengikuti postest menunjukkan bahwa uji-t dengan taraf signifikansi a $=0,05$ dan diperoleh $t_{\text {hitung }}=3,988$ sedangkan $\mathrm{t}_{\text {tabel }(0,05 ; \mathrm{N}-2)}$ $=2,024$ karena $t_{\text {hitung }}<t_{\text {tabel }}$ maka $\mathrm{H}_{0}$ ditolak artinya rata-rata postest kelompok eksperimen dan kelompok kontrol terdapat perbedaan yang signifikan. Maka dapat disimpulkan bahwa terdapat perbedaan antara siswa yang diberi media Flipchart dengan siswa yang diberi pembelajaran konvensional.

\section{SIMPULAN}

Hasil penelitian dan pengujian hipotesis menunjukkan bahwa media Flipchart dapat mempengaruhi pemahaman konsep IPA kelas IV, serta dapat membuat siswa menjadi lebih aktif dalam proses pembelajaran serta mampu menumbuhkan minat atau ketertarikan terhadap pembelajaran. Penggunaan media Flipchart akan memudahkan siswa memahami konsep yang diberikan oleh guru. Berdasarkan analisis statistik postest kelas eksperimen dan kelas kontrol dengan menggunakan uji-t dengan taraf 5\% didapatkan hasil $\mathrm{t}_{\text {hitung }}=3,988>\mathrm{t}_{\text {tabel }(0,05 ; \mathrm{N}-2)}=$ 2,024. Dari hasil penelitian tersebut dapat disimpulkan bahwa terdapat perbedaan pemahaman konsep IPA kelas IV SDN Kalideres 09 Pagi Jakarta Barat pada siswa yang diberikan media Flipchart dengan siswa yang diberikan pembelajaran secara konvensional. Dengan kata lain pembelajaran dengan media Flipchart memberikan pengaruh positif terhadap pemahaman konsep IPA kelas IV SDN Kalideres 09 Pagi Jakarta Barat.

\section{DAFTAR PUSTAKA}

Adilah, N. (2017). Perbedaan Hasil Belajar IPA melalui Penerapan Metode Mind Map dengan Metode Ceramah. Indonesian Journal of Primary Education, $\quad$ 1(1). https://doi.org/10.17509/ijpe.v1i1.7521

Budiastuti, D., \& Bandur, A. (2018). Validitas dan Reliabilitas Penelitian. Mitra Wacana Media.

Farida, I. (2017). Evaluasi Pembelajaran Berdasarkan Kurikulum Nasional. PT Remaja Rosdakarya.

Hardani, H., Medica, P., Husada, F., Andriani, H., Sukmana, D. J., Mada, U. G., \& Fardani, R. (2020). Buku Metode Penelitian Kualitatif \& Kuantitatif (Issue March).

Hendawati, Y., \& Kurniati, C. (2017). Penerapan Metode Eksperimen Terhadap Pemahaman Konsep Siswa Kelas V Pada Materi Gaya Dan Pemanfatannya. Metodik Didaktik, 13(1).

https://doi.org/10.17509/md.v13i1.7689 
Hildayani, D., Nurfadhillah, S., \& Tangerang, U. M. (2020). Pengaruh Media Film Strip terhadap Pemahaman Konsep IPA Kelas IV SDN Sukamaju. PENSA: Jurnal Pendidikan Dan Ilmu Sosial, 2(3), 272-282.

Kim, T. K. (2015). T test as parametric statistic. Korean J Anesthesiol, 68(6), 540-546.

Marhamah. (2016). Flipchart Sebagai Alternatif Media Untuk Meningkatkan Prestasi Belajar Matematika. Jurnal Dosen Universitas PGRI Palembang, 969-975.

Nurrita, T. (2018). Pengembangan Media Pembelajaran Untuk Meningkatkan Hasil Belajar Siswa. MISYKAT: Jurnal Ilmu-Ilmu Al-Quran, Hadist, Syari'ah Dan Tarbiyah, 3(1), 171. https://doi.org/10.33511/misykat.v3n1.1 71

Purwaningsih, K., Zaenuri, \& Hidayah, I. (2017). Analisis Kemampuan Pemahaman Konsep dalam Pembelajaran Contextual Teaching and Learning Materi Segiempat Ditinjau dari Tipe Kepribadian Peserta Didik. Unnes Journal of Mathematics Education, 6(1), 142-151.

https://doi.org/10.15294/ujme.v6i1.1264 2

Romlah, S. (2021). Penelitian Kualitatif Dan

Kuantitatif (Pendekatan Penelitian Kualitatif dan Kuantitatif). PANCAWAHANA: Jurnal Studi Islam, 16(1), 1-13.

Rudini, R. (2017). Peranan Statistika Dalam Penelitian Sosial Kuantitatif. Jurnal SAINTEKOM, $6(2)$ https://doi.org/10.33020/saintekom.v6i2 .13

Sudaryono, D. (2014). Aplikasi Statistik
Untuk Penelitian. Lentera Ilmu Cendekia.

Sugiyono, P. D. (2017). Metode Penelitian Kuantitatif, Kualitatif, dan $R \& D$. CV Alfabeta.

Sutopo, Y., \& Slamet, A. (2017). Statistik Inferensial. Andi.

Usmadi. (2020). Pengujian Persyaratan Analisis (Uji Homogenitas dan Uji Normalitas). Inovasi Pendidikan, 7(1), $50-62$.

Winarsunu, T. (2017). Statistik dalam Penelitian Psikologi dan Pendidikan. UMM Press. 